GA-A22048

\title{
EXPERIMENTALLY DETERMINED PROFILES OF FAST WAVE CURRENT DRIVE ON DIII-D
}

by

C.B. FOREST, C.C. PETTY, F.W. BAITY, S.C. CHIU, J.S. deGRASSIE, R.J. GROEBNER, H. IKEZI, E.F. JAEGER, K. KUPFER, M. MURAKAMI, R.I. PINSKER, R. PRATER, B.W. RICE, M.R. WADE, and D.G. WHYTE

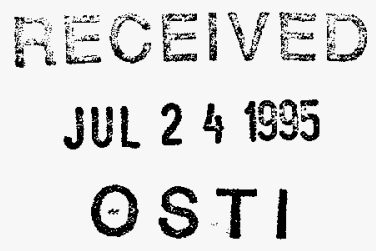

JUNE 1995 


\section{DISCLAIMER}

This report was prepared as an account of work sponsored by an agency of the United States Government. Neither the United States Government nor any agency thereof, nor any of their employees, make any warranty, express or implied, or assumes any legal liability or responsibility for the accuracy, completeness, or usefulness of any information, apparatus, product, or process disclosed, or represents that its use would not infringe privately owned rights. Reference herein to any specific commercial product, process, or service by trade name, trademark, manufacturer, or otherwise does not necessarily constitute or imply its endorsement, recommendation, or favoring by the United States Government or any agency thereof. The views and opinions of authors expressed herein do not necessarily state or reflect those of the United States Government or any agency thereof. 


\section{DISCLAIMER}

Portions of this document may be illegible in electronic image products. Images are produced from the best available original document. 


\section{EXPERIMENTALLY DETERMINED PROFILES OF FAST WAVE CURRENT DRIVE ON DIII-D}

by

C.B. FOREST, C.C. PETTY, F.W. BAITY,* S.C. CHIU, J.S. deGRASSIE, R.J. GROEBNER, H. IKEZI, E.F. JAEGER, K. KUPFER ${ }^{\dagger}$ M. MURAKAMI,* R.I. PINSKER, R. PRATER, B.W. RICE, ${ }^{\ddagger}$ M.R. WADE,* and D.G. WHYTE

This is a preprint of a paper to be presented at the 11th Topical Conference on Radio Frequency Power in Plasmas, May 17-19, 1995, Palm Springs, California, and to be printed in the Proceedings.

Work supported by U.S. Department of Energy Contracts DE-AC03-89ER51114, DE-AC05-840R21400, and W-7405-ENG-48

*Oak Ridge National Laboratory

†ORISE Postdoctoral Fellow

¥ Lawrence Livermore National Laboratory

Centre Canadien de Fusion Magnétique

GENERAL ATOMICS PROJECT 3466

JUNE 1995 


\title{
Experimentally Determined Profiles of Fast Wave Current Drive on DIII-D
}

\author{
C.B. Forest, C.C. Petty, F.W. Baity, ${ }^{*}$ S.C. Chiu, J.S. deGrassie, \\ R.J. Groebner, H. Ikezi, E.F. Jaeger, ${ }^{*}$ K. Kupfer, ${ }^{\dagger}$ \\ M. Murakami, ${ }^{*}$ R.I. Pinsker, R. Prater, B.W. Rice, ${ }^{\ddagger}$ \\ M.R. Wade, ${ }^{*}$ and D.G. Whyte \\ General Atomics, San Diego, California 92186 \\ * Oak Ridge National Laboratory, Oak Ridge, Tennessee 37831 \\ † ORISE Postdoctoral Fellow at General Atomics \\ ${ }^{\ddagger}$ Lawrence Livermore National Laboratory, Livermore, California 94551 \\ "Centre Canadien de Fusion Magnétique, Québec, Canada
}

\begin{abstract}
Profiles of non-inductive current driven by fast waves have been determined for reversed-shear DIII-D discharges. Both the current profile and toroidal electric field profile are determined from time sequences of equilibrium reconstructions [C.B. Forest et al., Phys. Rev. Lett. 73, 2224 (1994)]. Using this information, the measured current profile has been separated into inductive and non-inductive portions. By comparing similar discharges with co and counter antenna phasings and similar fast wave power, the portion of the total non-inductive current driven by fast waves was determined. The experimentally determined profiles of FWCD are in general agreement with theoretical predictions. Specifically, $135 \mathrm{kA}$ was driven by $1.4 \mathrm{MW}$ of $\mathrm{rf}$ power with a profile peaked inside $\rho=2$.
\end{abstract}

To obtain and maintain steady-state current profiles which improve tokamak performance - a main objective of the advanced tokamak research on DIII-D - non-inductive current drive sources with suitable profiles must be developed [1]. The purpose of this work is to determine the profile of fast wave current drive (FWCD) and compare this profile to various FWCD models.

DIII-D discharges with early neutral beam injection and a period of reversed central magnetic shear are well suited for measurements of if driven currents by the method described in Ref. 2. The time histories for such a plasma with toroidal field of $2.1 \mathrm{~T}$ and a plasma current of $1.4 \mathrm{MA}$ are shown 
in Fig. 1. Neutral beam injection begins during the current ramp (300 msec after breakdown), providing motional Stark effect (MSE) measurements for equilibrium reconstruction [3] and heating the plasma. Central electron temperatures reach $5 \mathrm{keV}$ while the central density is kept below $2.5 \times 10^{13} \mathrm{~cm}^{-3}$. These plasma parameters are suitable for efficient current drive using the two If systems - a $60 \mathrm{MHz}$ source and a $90 \mathrm{MHz}$ source [4], each injecting up to $1 \mathrm{MW}$ of power with launched antenna spectra maxima at $n_{\|}$of 4.7 and 4.0, respectively. The direction of launched rf power can be changed between shots from co current drive to counter current drive. In all cases, the neutral beam driven current is in the same direction as the plasma current (co). The rf power is injected beginning at the start of current flattop as indicated in Fig. 1(b). The minimum value of the safety factor $q_{\min }$ and the value on axis $q_{0}$ are shown in Fig. 1 (d); early in the discharge $q_{\min }$ is smaller than $q_{0}$, so that the discharge has a central region of reversed magnetic shear. The onset of sawteeth at $2.5 \mathrm{sec}$ (as seen on the electron temperature evolution) coincides with $q_{\min }$ falling below $1^{*}$.

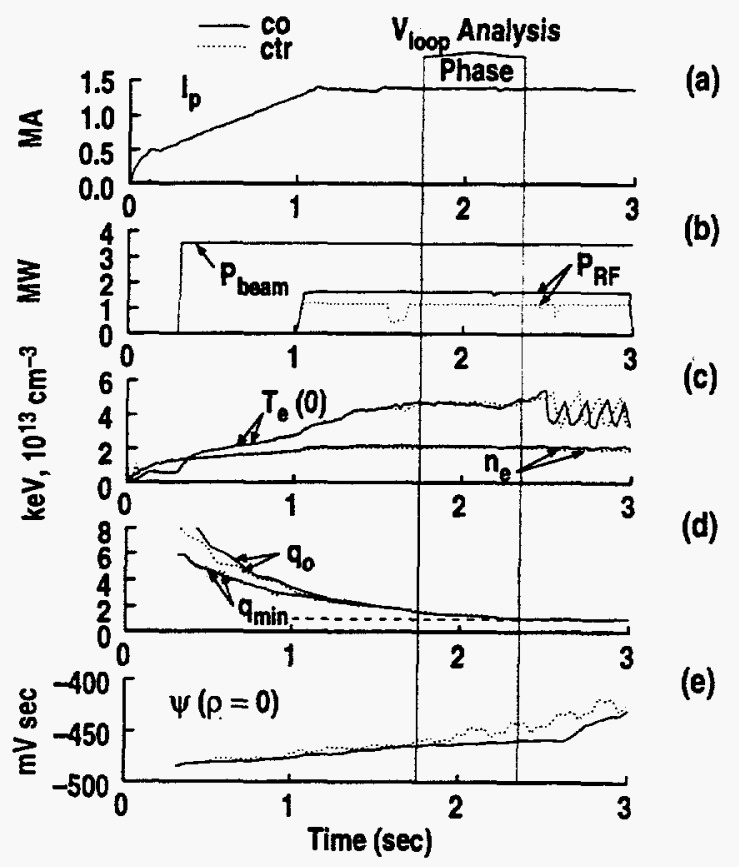

FIGURE 1. The time evolution of (a) the total plasma current, (b) the total injected neutral beam power and if power, $(c)$ the central electron temperature $T_{e}(0)$ and density $n_{e}(0)$, (d) $q_{0}$ and $q_{\min }$ determined from equilibrium reconstructions, and (e) the central value of poloidal flux $\left(\psi_{0}\right)$ for co and counter current drive phasings. The discharge is a single null divertor, $B_{\tau}=2.05 \mathrm{~T}$, deuterium plasma.

*To measure the non-inductive current due to FWCD by the method described in Ref. 2, the evaluation of the current and poloidal flux profiles must be governed by resistive relaxation as opposed to $\mathrm{MHD}$ events which move current. 
The loop voltage profiles and non-inductive current profiles have been determined for several discharges with co and counter current drive. Using the code EFIT [5], time sequences of equilibria are reconstructed from magnetic probe data (including internal measurements by MSE) and pressure profile. From these time sequences, the current profile is determined as well as the internal parallel electric field (from the time derivative of poloidal flux) [2]. Figure 1(e) shows the poloidal flux at the magnetic axis for co and counter current drive - it is the time derivative of this quantity which is related to the local electric field - and shows that the loop voltage is larger on axis for counter than for co. Figure 2 shows the current density (a) and loop voltage (b) profiles for two nearly identical discharges with co and counter current drive. The loop voltage profiles are determined during the period starting at $1.7 \mathrm{sec}$ and ending at $2.2 \mathrm{sec}$ (as indicated in Fig. 1).

The presence of if driven currents is discernable on the current profile, but it is much more obvious on the loop voltage profile. At this time in the discharge, the value of $q$ in the central region is larger for counter current drive than for co $(\Delta q \sim 0.2)$. Although this difference is modest, the loop voltage profiles are very different in the central region. The larger loop voltage in the counter case indicates a larger fraction of inductively driven current is present. In both cases, the plasma is far from resistive equilibrium (defined by a loop voltage profile which is constant in space) and the current profiles are peaking with time. Note that the loop voltage on the boundary of the plasma is nearly identical for both co and counter, so that an analysis based solely on the loop voltage at the boundary of the plasma would not indicate any current drive.

The non-inductive current density profile, determined by subtracting the inductive current density (the product of the loop voltage and the resistivity determined from neoclassical resistivity through measured electron temperature and $Z_{\text {eff }}$ profiles) from the total current density, is similar to predictions from theoretical models. The non-inductive current is the sum of the neutral beam driven current, the bootstrap current and the fast wave driven current. To separate the fast wave driven current from the other
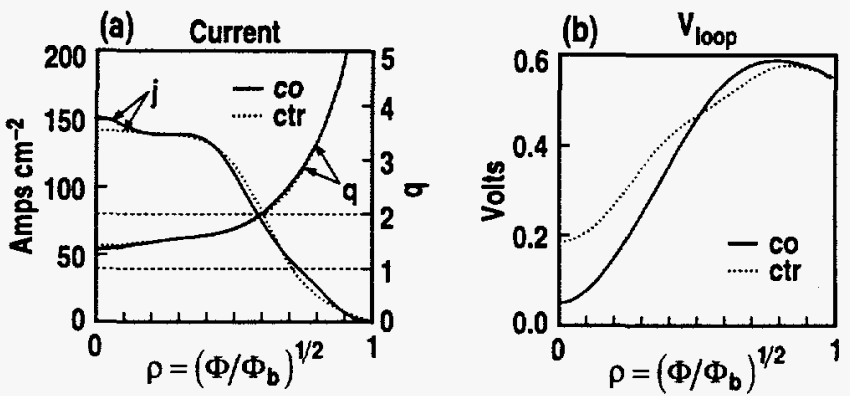

FIGURE 2. (a) The current density and corresponding safety factor profiles for co (solid) and counter (dashed) cases at $2.1 \mathrm{sec}$; (b) the loop voltage profile determined during the period from 1.7 to $2.2 \mathrm{sec}$ for co (solid) and counter (dashed) current drive. 
non-inductive currents, the difference between co and counter is calculated and multiplied by $P_{\text {co }} / P_{\text {co }}+P_{\text {counter }}$ to determined the portion due to co rf. Figure 3 shows the experimentally determined $\mathrm{rf}$ driven current profile for 1.4 MW of injected if power. Figure 3 also shows predictions from a model based on the ergodic limit of weakly damped rays (FASTCD) [6], a ray tracing code with multiple reflections (CURRAY) [7], and the results from full wave code (PICES) [8]. Total integrated current from this profile is $110 \mathrm{kA}$ corresponding to a total efficiency $\eta \equiv \bar{n}_{\mathrm{e}} I_{\mathrm{rf}} R / P_{\mathrm{rf}} \simeq 2.7 \times 10^{18} \mathrm{AW}^{-1} \mathrm{~m}^{-2}$ in approximate agreement with previous results extrapolated to higher electron temperatures [9].

This is a report of work supported by U.S. DOE Contracts DE-AC0389ER51114, DE-AC05-84OR21400, and W-7405-ENG-48, and in part by an appointment to the U.S. Department of Energy Fusion Energy Postdoctoral Research Program at General Atomics administered by the Oak Ridge Institute for Science and Education.

\section{REFERENCES}

[1] T.S. Taylor et al., Plasma Phys. and Contr. Fusion 36, B229 (1994).

[2] C.B. Forest et al., Phys. Rev. Lett. 73, 2444 (1994).

[3] D. Wróblewski et al., Rev. Sci. Instrum. 63, 5140 (1992).

[4] J.S. deGrassie et al., in Proc. 15th IEEE/NPSS Symp. on Fusion Engineering, Piscataway, 1993, Vol. 2, p. 1073.

[5] L.L. Lao et al., Nucl. Fusion 30, 1035 (1993).

[6] K. Kupfer et al., Phys. Fluids B 73, 3915 (1994).

[7] T.K. Mau et al., in Proc. EPS Top. Conf. on RF Heating and Current Drive of Fusion Devices, Brussels, Belgium, 1992, Vol. 16E, p. 181.

[8] E.F. Jaeger et al., Nucl. Fusion 33, 179 (1993).

[9] R.I. Pinsker et al., in Plasma Physics and Controlled Nuclear Fusion Research Würzburg, 1992 (Proc. 14th Int. Conf.), p. 683.

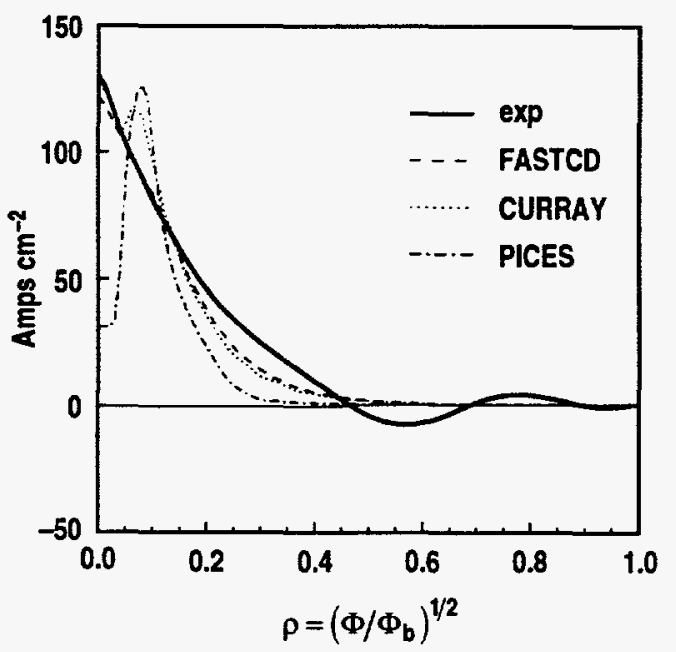

FIGURE 3. The experimentally determined non-inductive current profile due to FWCD and theoretical predictions from stochastic limit model and full wave code. 